\title{
Performance Prediction Of 5g: The Next GENERATION OF MOBILE COMMUNICATION
}

\author{
Sardar Irfanullah A ${ }^{1}$, Gul Shaira Banu ${ }^{2}$ andAmjath Fareeth ${ }^{2}$ \\ ${ }^{1}$ Department of Computer Sciences and Engineering, Yanbu University College, \\ Royal Commission for Yanbu Colleges and Institutes, Saudi Arabia \\ ${ }^{2}$ College of Computers and Information Technology, Taif University, Saudi Arabia
}

\begin{abstract}
The $5 G$ standard is a mobile communication of the $5^{\text {th }}$ generation, which presupposes an increase of the information exchange speed up to $10 \mathrm{Gbit} / \mathrm{s}$. It is 30 times quicker than the speed of $4 \mathrm{G}$ network. It is a new stage in the development of technologies connecting society. This standard will provide an unlimited access to the network for individual users and devices. When developing the $5 G$ standard, the advanced opportunities of LTE and HSPA, as well as other technologies of a radio access focused on the solution of specific objectives are considered. The main advantage of the mass introduction of the $5 G$ communication development represents the so-called Internet of Things (IoT). There the devices and not people will be the main consumers of traffic. The functional requirements of $5 G$ networks, their speed, and its traffic parameters for $H D$ video services and massifs of $M 2 M$-devices are analyzed in the paper. They will have been the most demandedones by 2020.
\end{abstract}

\section{KEYWORDS}

$5 G$, ultra-dense networks (UDN), M2M networks, quality of service (QoS), Internet of Things (IoT)

\section{INTRODUCTION}

There is the global growth of mobile devices, such as smartphones and tablet computers, observed. Therefore, there is an increasing need of users for the transfer of large volumes of data for the networks of mobile cellular communication and the wireless Internet access. As a result of such development, the producers of telecommunication equipment and operators meet the constantly growing demands to the quality of services for users. It is a driving factor in the evolution. Moreover, it is a fast change of technological generations and standards of mobile communication as well as the systems of wireless data transmission [4].

At present, there is an active development of networks of wireless mobile communication of the $3^{\text {rd }}$ and $4^{\text {th }}$ generations. According to the forecasts of experts, by 2018, the information transfer volume will have increased in the systems of mobile communication more than by 12 times in comparison with the level of 2015[1]. Therefore, the active researches of new technologies of wireless data transmission for the systems of mobile communication of the $5^{\text {th }}$ generation have begun recently. The main tool for the evolution and assessment of the quality of wireless mobile communication systems represents the numerical modelling carrying out the imitation of work of the communication system. A set of simultaneously operating transmitters and receivers for various scenarios of the expansion of mobile networks should be taken into account [5]. The 
given research paper will discuss the performance analysis of the $5 \mathrm{G}$ technology, based on the speed and traffic tools, as well as comparison with the $3 \mathrm{G}$ and $4 \mathrm{G}$ networks.

\section{General Characteristics Of The 5g Technology}

At present, the networks of mobile communication have been built on the standards of the $2^{\text {nd }}$ generation (2G) GSM (Global system of mobile communication) and the $3^{\text {rd }}$ generation $(3 \mathrm{G})$ UMTS (Universal System of Mobile Communication) as well as the IEEE 802.11a/g and 802.11n standards of wireless networks. They are considered to be the most widely used [7]. These networks are gradually followed by the systems of mobile communication of the new $4 \mathrm{G}$ generations and the new norms of the wireless IEEE 802.11ac and 802.11ad.They are providing the higher rates of productivity and quality of service (Figure 1).

\begin{tabular}{|c|c|c|c|c|c|c|c|}
\hline Generations & $1 G$ & $2 \mathrm{G}$ & $2.5 \mathrm{G}$ & $3 G$ & $3.5 \mathrm{G}$ & $4 G$ & $5 G$ \\
\hline $\begin{array}{c}\text { Start/Deployme } \\
\mathrm{nt} \\
\end{array}$ & $\begin{array}{l}1970- \\
1980\end{array}$ & $1990-2004$ & $\begin{array}{l}2001- \\
2004\end{array}$ & $2004-2010$ & $\begin{array}{l}2006- \\
2010\end{array}$ & 2010-Now & Soon \\
\hline Data Bandwidth & $2 \mathrm{Kbps}$ & 9.6- $43.2 \mathrm{Kbps}$ & $\begin{array}{c}144- \\
384 \\
\text { Kbps }\end{array}$ & 2Mbps & $\begin{array}{l}\text { More } \\
\text { than } \\
\text { 2Mbps }\end{array}$ & $1 \mathrm{Gbps}$ & $\begin{array}{l}\text { Higher } \\
\text { than } \\
\text { 1Gbps }\end{array}$ \\
\hline Technology & $\begin{array}{c}\text { Analog } \\
\text { Cellular } \\
\text { Technolog } \\
\text { y }\end{array}$ & $\begin{array}{c}\text { Digital } \\
\text { CellularTechnolo } \\
\text { gy }\end{array}$ & $\begin{array}{l}\text { GPRS, } \\
\text { EDGE } \\
\text { CDM } \\
\text { A }\end{array}$ & $\begin{array}{c}\text { CDMA } \\
\text { 2000(1xRTT } \\
\text { EVDOUMT } \\
\text { S, EDGE }\end{array}$ & $\begin{array}{l}\text { EDGE, } \\
\text { Wi-Fi }\end{array}$ & $\begin{array}{l}\text { Wi-Max, } \\
\text { LTE, LTE-A, } \\
\text { Wi-Fi }\end{array}$ & WWWW \\
\hline Service & $\begin{array}{l}\text { Mobile } \\
\text { Telephon } \\
\text { y (Voice) }\end{array}$ & $\begin{array}{l}\text { Digital voice, } \\
\text { SMS, Higher } \\
\text { capacity } \\
\text { packetized data }\end{array}$ & $\begin{array}{l}\text { SMS, } \\
\text { MMS }\end{array}$ & $\begin{array}{l}\text { Integrated } \\
\text { high quality } \\
\text { audio, } \\
\text { video and } \\
\text { data }\end{array}$ & $\begin{array}{l}\text { Integrate } \\
\text { d high } \\
\text { quality } \\
\text { audio, } \\
\text { video } \\
\text { and data }\end{array}$ & $\begin{array}{c}\text { Dynamic } \\
\text { Informatio } \\
\mathrm{n} \text { access, } \\
\text { Wearable } \\
\text { devices }\end{array}$ & $\begin{array}{c}\text { Dynamic } \\
\text { Informatio } \\
\mathrm{n} \text { access, } \\
\text { Wearable } \\
\text { devices } \\
\text { with Al } \\
\text { Capabilitie } \\
\text { s }\end{array}$ \\
\hline Multiplexing & FDMA & TDMA, CDMA & $\begin{array}{c}\mathrm{CDM} \\
\mathrm{A}\end{array}$ & CDMA & CDMA & $\begin{array}{l}\text { OFDMA, } \\
\text { SCFDMA }\end{array}$ & $\begin{array}{l}\text { OFDMA, } \\
\text { SCFDMA }\end{array}$ \\
\hline Switching & Circuit & Circuit, Packet & $\begin{array}{c}\text { Packe } \\
\mathrm{t}\end{array}$ & Packet & $\begin{array}{c}\text { All } \\
\text { Packet }\end{array}$ & All Packet & All Packet \\
\hline Core Network & PSTN & PSTN & PSTN & $\begin{array}{l}\text { Packet } \\
\text { N/W }\end{array}$ & Internet & Internet & Internet \\
\hline
\end{tabular}

Figure 1. Generations of mobile technologies [9]

Besides, the development of the 3G+HSPA (High-Speed Packet Transmission of Data) standard is considered by the experts as one of the transitional migratory stages to the technologies of mobile communication of the $4^{\text {th }}$ generation[5].It is a superstructure over the UMTS 3 G network. The recent researches of new technologies for the systems of mobile communication of the $5^{\text {th }}$ generation $(5 \mathrm{G})$ have already started. Their spread is supposed to be carried out in 2020 . There is a process of evolution of mobile communication technologies and wireless networks from 1990 to 2020 (Figure 2)[1]. 


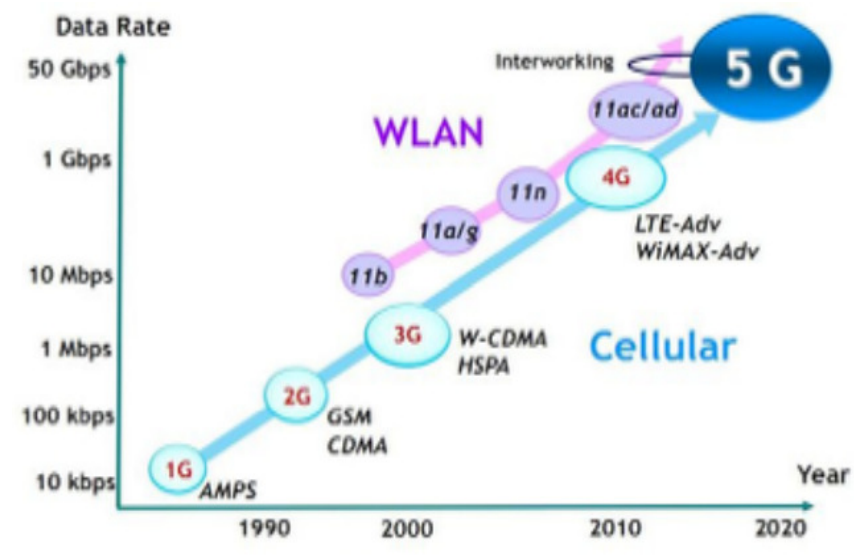

Figure2. Mobile communication system in 1990-2020[1].

The 5G technologies should considerably improve the quality of service (QoS) of users. This enhancement is related to the conditions of many growing volumes of the transmitted data in mobile networks and also an increase in the number of wireless devices. Therefore, it expands the range of provided services [7]. The networks of mobile communication built on the basis of 5G technologies are expected to provide the transfer of information with the speed of more than 10 Gbit/s[4].

The forecasts of leading experts engaged in the international 5G projects show the following facts. The dominant position among the services rendered in $5 \mathrm{G}$ networks will be occupied by the services of the HD transfer and 3D - video. The reports of the world leading telecom operators using the $4 \mathrm{G}$ networks display that video service consumed by subscribers prevail in the traffic. It will remain dominating in the content of 5G networks [1]. Besides, by 2020, the number of M2M connections is supposed to increase with the CAGR indicator - $45 \%$-in the networks of mobile operators. Taking into account the growing mass character (Massive M2M), the M2M service will prevail over the basic voice services in $4 \mathrm{G}$ and $5 \mathrm{G}$ networks [10].

The European 5G development strategy is directed at the provision of choice for subscribers. They should decide what should be connected to the TV, i.e. a modern $5 \mathrm{G}$ or radio antenna. Accordingly, it will demand the corresponding mechanisms of quality management. Thus, the efforts of developers on the improvement of quality instruments will concentrate on the video traffic and M2M-services, enhancement of controlling algorithms, and the creation of new methods of quality assessment [5].

\subsection{G SPEED}

The development of $5 \mathrm{G}$ networks will be directed at the formation of ultra-dense networks (UDN) of a wireless access with the heterogeneous structure of cells. Their radius will compose 30-49 meters on the basis of new types of alarm and code designs for radio signals. It is much increasing the spectral efficiency in comparison with the $4 \mathrm{G}$ networks and providing data transmission with the speed more than $10 \mathrm{Gbit} / \mathrm{s}$ [10]. In order to ensure such speed of data transmission in $5 \mathrm{G}$ networks, it will be required to use the wide strips of channels both in the DL line and in the UL line with a continuous range from 500 to $1000 \mathrm{MHz}$. It will 25-50 times exceed the width of channels realized in 4G [9]. 
The characteristics of requirements to the spectral efficiency in the cell of5G networks for various channels of transfer are shown in the Figure 3. The detailed comparison of these features to $4 \mathrm{G}$ networks represents an increase of efficiency by the least 3 times. The infrastructure of $5 \mathrm{G}$ networks will be based on the cloud computing, the networks of the radio access (Cloud RAN) with the program defended network (Software Defended Radio, SDR), and basic network (Cloud $\mathrm{CN}$ ) with the program defined infrastructure (Software Defended Network, SDN). The full virtualization of network functions (Network Function Virtualization, NFV), which will be realized in the $5 \mathrm{G}$ infrastructure, will capture the QoS, the policy of service, and traffic prioritization [11].

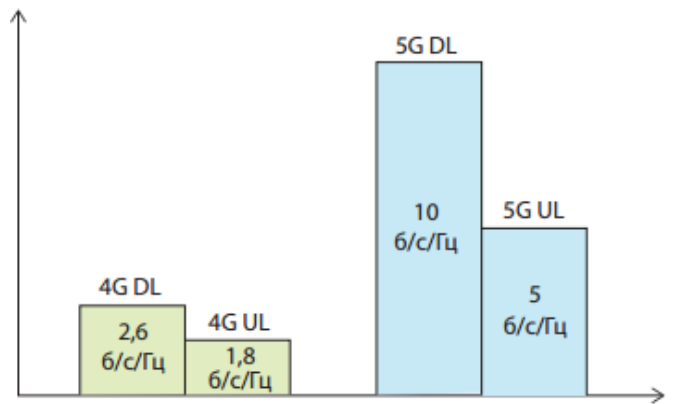

Figure3. The spectral efficiency of $5 \mathrm{G}$ networks in a cell [11]

Moreover, the new solutions will appear together with the arrival of 5G networks. The moving knots (base stations) of communication (Moving 5G Node) and moving transport networks (Moving 5G Backhaul) are needed for the introduction of the 5G technology during the creation of intellectual transport networks. These decisions will allow equipping the international mobile highways with the cars rushing on them with the speed more than $200 \mathrm{~km} / \mathrm{h}$. Constructed on the basis of the applications and M2M devices for the V2V (Vehicle-to-Vehicle) scenario, they will provide the safe trips and multimedia data exchange[8]. The base stations of5G will be represented by the $5 \mathrm{G}$ automobile devices united in mesh-networks.

The 5G network is expected to support the maximum speed of data transmission up to $20 \mathrm{Gbit} / \mathrm{s}$. The methods of MU-MIMO, F-OFDM and SCMA are widely applied for an increase of efficiency of broadband communication systems. Moreover, they present the mass implementation of the intermachine communications as well as some crucial and reliable communication devices for the realization of 5G networks. Verizon, an American cell communication operator, will become the first mobile analyst who will start to test the $5 \mathrm{G}$ network [1].

The stratospheric stations HAPS (High Altitude Stratospheric Platform Stations) will be used instead of earth-based ones existing for the application of $2 \mathrm{G}, 3 \mathrm{G}$ and $4 \mathrm{G}$ networks. They are the aircrafts, which soar in the air somewhere in between 17-22 km from the Earth's surface. Moreover, they work as the satellites providing communication covering [8]. They will provide the direct channels for a signal and reduce the hindrances created by high constructions. Besides, owning to the height, the base stations can cover big areas, thus reducing the problems of the signal distribution if there are no hindrances. Even in the sea, where the terrestrial towers are not capable to transmit any call, the covering with HAPS will be possible. 


\section{TRAFFIC IN 5G NETWORKS}

The main tendency represents the growth of the transmitted data volume in the networks of mobile operators. In 2010, the volume date traffic in the world was only twice more than such one of the voice traffic [12]. However, everything cardinally changed five years ago. The quarterly world growth of traffic in the networks of mobile operators of 2010-2015 is presented in the Figure 4[15].

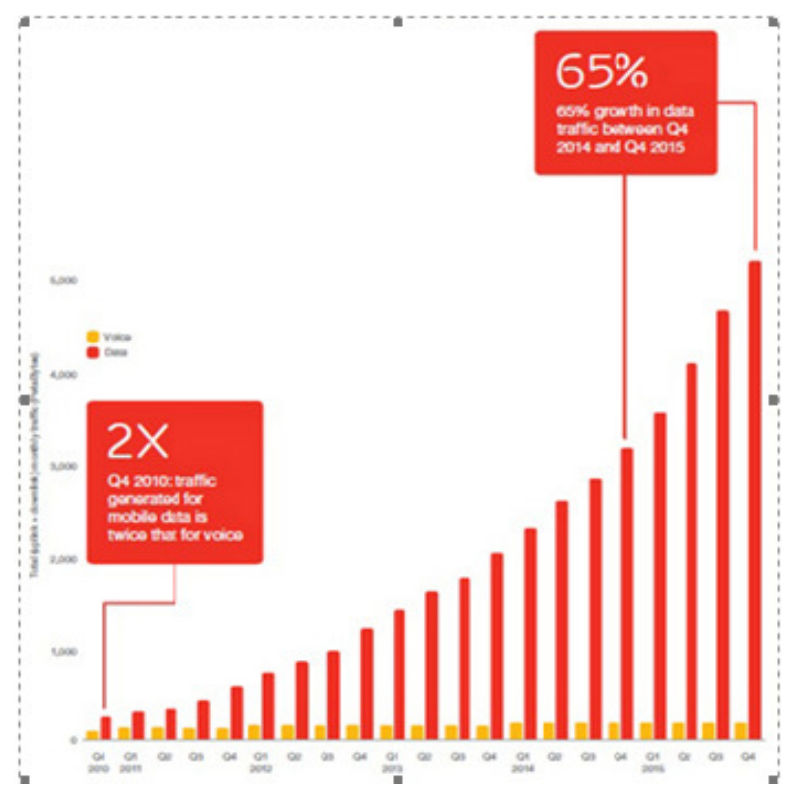

Figure. 4 The quarterly world growth of traffic in the networks of mobile operators, 20102015[15].

It occurred due to the creation of $3 \mathrm{G}$ networks and LTE by mobile operators. The development continues leading to the growth of volumes of traffic up to $45 \%$ until 2021. In its turn, traffic consists of video by $75 \%$ [5]. The high share of such content is connected with the annual emergence of more powerful and perfect gadgets. Their owners seek to download or watch HD video. They also exchange their own one [15].

In the course of evolution of the quality management mechanism of $3 \mathrm{G}$ networks (GSM/UMTS/LTE), there was the migration from the QoS control at the level of subscriber terminals to the QoS one of the network [7]. This approach will also remain in 5G networks. The mechanisms of the QoS management in 5G networks have to provide the prioritization of traffic of video over $5 \mathrm{G}$ and VoIP in relation to the traffic of the web search. The video transfer service is rather sensitive to the delays in web. Therefore, one of the major parameters defining the requirements to QoS includes the Packet Delay Budget (PDB). It is based on the RAN radio that is considered to be the maximum delay of the packets' transfer with the high level of reliability composing $98 \%$ [8].

Social networks have become the second important source of the 5G traffic. Their share makes about $15 \%$. It is not expected to be changed for the following five years. The active subscriber from Central and Eastern Europe consumes about $2 \mathrm{~GB}$ of the traffic per month. In five years, an active borrower will use 6 GB of data monthly [14]. 
To provide the processing of the big volume of user's traffic in several $\mathrm{Gb} / \mathrm{s}$, the introduction of the ultra-dense expansion of networks ranges of the frequencies by means of new radio technologies. Within them, the base stations will use a wide bandwidth in the top. The ultra-dense networks will consist of the low-power base ones established with a much higher density in comparison with the ones existing nowadays. In extreme cases, the base stations will be established in each room [3]. The ultra-dense networks will provide the bandwidth not lower than several hundred $\mathrm{MHz}$ with a possibility of expansion to several $\mathrm{GHz}$ for the reliable support of Gigabit speeds. They will work mainly in the range of $10-100 \mathrm{GHz}$ [15].

The high-frequency ranges facilitate the problem of ensuring the wide bandwidth necessary to maintain the Gigabit speeds of data transmission. The ultra-dense networks will include the application of advanced network solutions. Despite the fact that such networks will work in the other diapason and, most likely, will be founded on new technologies of the radio access, they have to be well-integrated. They need to have the already constructed level of cellular networks. At the same time, a user should not feel any discomfort when moving from a cover zone of ultradense networks and back [12].

When forming the requirements to the QoS in $5 \mathrm{G}$ networks, it is necessary to consider the following facts. Two key models of traffic: a high-speed video stream server-subscriber and Massive M2M should be taken into consideration. The services of video transfer will become the most important incentive for the development of the fast-growing segment of the traffic of $5 \mathrm{G}$ networks. In 2013, the volume of video services in the total amount of traffic of 4G networks exceeded 50\%.It will have grown at least by 13 times by 2019[1].

The monthly consumption of data transmission traffic in $4 \mathrm{G}$ networks reached 2, 6 Gbit. The use of traffic per month in 5G networks will exceed 500 Gbit. According to Lin, Gao, Huang, et al. (2015), the growth of the volume of traffic of video services will be connected with the introduction of new technologies of the video quality improvement, i.e.- from the standard SDTV up to ultrahigh UHD TV $(8 \mathrm{~K})$. In its turn, it demands the ensuring speed of data transmission in the network up to $10 \mathrm{Gbit} / \mathrm{s}$ [8]. The number of M2M-connections of mobile operators in 2018 will have exceeded 1.5 billion. It is five times more than the current indicator. In 2022, this number is expected to increase up to 2, 6 billion of M2M-connections. At the same time, their share from the total number of connections in the networks of mobile operators will have grown from the current $5 \%$ to $15 \%$ in 2018 and $22 \%$ in 2022[13].

\section{Advantages OF 5G}

The main advantage of $5 \mathrm{G}$ consists in the ability to effectively adapt to the wide range of requirements shown by new applications. Their safe operation with the increased demands to the reliability intended, for example, for the road safety is possible due to the reduction of response time of the network infrastructure to several milliseconds (Ericsson 2015).The acceleration of the data transfer speed will become the main task of the 5G technology. Such network will be necessary for the compatible work of several types of devices at once: corporate systems, personal devices, and various types of equipment called Internet of Things (IoT).

The Internet of Things (IoT) has also been discussed as a key differentiator for 4G. However, in reality, the challenge of providing low power and low frequency networks to meet the demands for the widespread M2M deployment is not specific to $4 \mathrm{G}$ or $5 \mathrm{G}[6]$. 
Another advantage of $5 \mathrm{G}$ for users consists in the fact that the gadgets will spend less energy for the data transmission than in the $3 \mathrm{G}$ and $4 \mathrm{G}$ technologies. The number of devices simultaneously connected to the base station will 1000 times increase in comparison with 4G [2]. The delays in the transfer of data package will be five-ten times lower. Moreover, the capacity of network will grow by ten hundred times.

It is supposed that the completely modified 5G network will support the exchange of information at the speed with hundreds of times exceeding the possibilities of $4 \mathrm{G}$ networks. In some cases, the speed of 5G can exceed $10 \mathrm{Gbit} / \mathrm{s}$. In the city conditions, it is about $100 \mathrm{Mbit} / \mathrm{s}$. Meanwhile in other areas, including sparsely populated rural places both in the developed and developing countries, the speed of data transmission is expected to be not lower than $10 \mathrm{Mbit} / \mathrm{s}$ [6].

Except for this fact, representing the main advantage of 5G, the new technology will be more responsive than $4 \mathrm{G}$. It is also expected that the new generation of mobile communications will be 10 times more energy-saving. It will positively influence the device service time. Complexity will become another key advantage of 5G [13]. It is created for the work with any types of traffic and provides the minimum postpone. It makes it ideal for the wearable technologies, clever home devices, and cars connected to the Internet.

Besides, the 5G technology will allow using the limited frequency resources much more effectively to reduce the cost of the certain information volume transfer. Therefore, the introduction of technology is expedient also in rather poor countries. Many services will be provided only in the 5G networks. They will be used by individual users for education, health care, transport, different industries, as well as also agriculture, the financial sphere, and other areas [14].

The new technology will also allow subscribers to watch the online content requiring the connection at big speeds. For example, it includes 3D - movies of high resolution or the live video broadcast. However, $5 \mathrm{G}$ is not just the modification of $4 \mathrm{G}$ or the fast mobile Internet [2]. First of all, the communication of the $5^{\text {th }}$ generation will provide the infrastructure for automated devices connected to the Internet of cars, pilotless electric automobiles, and other things. At the emergence of $5 \mathrm{G}$, there will be no dependence on wire networks and hardware video terminals. Moreover, the bigger number of participants will be able to have the qualitative picture and ampler opportunities for the interaction [6].

\section{Future Challenges}

The security and privacy of devices, infrastructures, communication, and information transfer is yet to be explored. The current solutions based on encryption would not suffice in the future due to a large number of devices. The development of network devices, IoT, infrastructures, and algorithms must be self-configuring, self-healing, and self-optimizing to preform dynamic operations as per the need, for example, QoS guarantee, dynamic load balancing, pooling of residual resources and traffic management. The latency is a primary concern in most of the realtime applications and services, especially, in the tactile Internet and IoT. Achieving the zero latency in all the existing architectures and implementations of 5G networks is a big challenge.

Other than above listed challenges, there are few more challenges has to be take into consideration like

Air Interface: New waveforms, New Frame structures, Interference Mitigation Techniques, Massive MIMO and Coding. 
Radio Propagation Considerations: Spectrum and Channel Modeling.

Implementation Challenges: Digital Signal processing, Transceiver design and implementation of Massive MIMO and beam forming.

\section{CONCLUSION}

The launch of $5 \mathrm{G}$ networks is planned by the year 2020 in the global market. They will be focused on the steady improvement of characteristics of communication technologies, including the qualities of service, speed, and volumes of traffic. The algorithms of the traffic classification will become another direction for the development of $5 \mathrm{G}$ networks. They will provide the support of the market demand for the services and needs of subscribers. The implementation of the $5 \mathrm{G}$ project by 2020 will create an unlimited access to any possible information. It is obvious that it will be necessary to solve the issue of the increasing amount of devices connected to the network to realize this activity. The variety of attached units, applications, and tasks allows assuming the following fact. The $5 \mathrm{G}$ technology will become the result of the existing technologies integration of radio access improved by LTE and HSPA. Thus, the gradual transition to such $5 \mathrm{G}$ networks can start in 2020.

\section{REFERENCES}

[1] Boccardi. F, Heath. RW, Lozano. A, Marzetta. TL\& Popovski. P, "Five disruptive technology directions for 5G”, IEEE Communications Magazine, vol. 52, no. 2, pp.74-80. 2014

[2] Churi. JR, Surendran.ST, Ajay Tigdi. S \& Yewale. S, "Evolution of networks (2G-5G)",Proceedings on International Conference on Advances in Communication and Computing Technologies (ICACACT), pp.8-13. 2012

[3] Ericsson 2015, "5G Systems", Ericsson White Paper, [viewed 08-January2017], <https://www.ericsson.com/co/res/docs/whitepapers/what-is-a-5g-system.pdf>.

[4] Guist. F Cominardi. L \& Bernardos, CJ, "Distributed mobility management for future 5G networks: overview and analysis of existing approaches",IEEE Communication Magazine, vol 53, No. 2pp. 142 149. 2015

[5] GSA 2015, "The road to 5G: Drivers, applications, requirements and technical development", A GSA Executive Report from Ericsson, Huawei and Qualcomm, [viewed 18 October 2016], <http://www.huawei.com/minisite/5g/img/GSA_the_Road_to_5G.pdf>.

[6] GSMA Intelligence 2014, "Understanding 5G: perspectives on future technological advancement in mobile", [viewed 17 October 2016], <https://www.gsmaintelligence.com/research/?file=1412085g.pdf\&download>.

[7] Hussein. M, Moubayed. A, Primak. S \& Shami. A,"Virtualized allocation performance analysis in 5G two-tier cellular networks", 29th Annual IEEE Canadian Conference on Electrical and Computer Engineering (CCECE 2016), at Vancouver, Canada,2016

[8] Lin. Z, Gao. Z, Huang. L, Chen. C-Y \& Chao. H-C. "Hybrid architecture performance analysis for device-to-device communication in 5G cellular network", Mobile Networks \& Applications, vol. 20, no. 6, pp. 713-724. January 2015

[9] Maskooki. A, Sabatino.G \& Mitton. N,“Analysis and performance evaluation of the next generation wireless networks",Modeling and Simulation of Computer Networks and Systems: Methodologies and Applications, 2015

[10] Maso. M \& Imran. MA, "Emerging topics in 5G networks: spectral and energy efficient network architecture, transceiver and algorithm design", European Conference on Networks and Communication, Athens, Greece, June 2016

[11] Anwar M Mousa, "Prospective of fifth generation mobile communications", International Journal of Next Generation Networks (IJNGN), vol.4, no.3. September 2012

[12] Ponram. E \& Naidu. R, “Advanced features \& future of wireless networks - 5G”, International Journal of Engineering Trends and Applications (IJETA), vol.1, no.1. July -August 2014 
International Journal of Next-Generation Networks (IJNGN) Vol.9, No.1, March 2017

[13] Soldani D 2016, "5G \& mobile network developments consultation number: 5G/2016 Huawei Australia submission", Huawei, [viewed 17 October 2016], <http://www.acma.gov.au/ /media/Research\%20and\%20Analysis/Issue\%20for\%20comment/pdf/5G $\% 20$ submission\%20Huawei\%20pdf.pdf $>$.

[14] Xiaofei. W, Min. C, Taleb. T, Ksentini. A \& Leung "Cache in the air: exploiting content caching and delivery techniques for 5G systems”,IEEE Communications Magazine, vol. 52, no.2, pp. 131-139 February 2014

[15] Zuniga. J, Bernardos. C, de la Oliva. A, Melia. T, Costa. R \& Reznik. A, "Distributed mobility management: A standards landscape”,IEEE Communications Magazine, vol. 51, no. 3, pp. 80-87. March 2013 